\title{
Rational Use of Smart Phone in English Learning
}

\author{
Xu Wenyu \\ School of Foreign Languages \\ North China Electric Power University \\ Beijing, China \\ 845899256@qq.com
}

\author{
Lyu Liangqiu \\ School of Foreign Languages \\ North China Electric Power University \\ Beijing, China \\ llq2803@163.com
}

\begin{abstract}
The smart phone, a tiny electronic device working like a computer, has gained more and more popularity amongst people, especially young students. Other than functions like communication and entertainment, the smart phone has greater and deeper influences in various activities of modern society, for instance, it also plays an essential role as a platform for foreign language learning, especially for studying English. This essay is going to analyze the impacts of using smart phones in English language studying and to provide some constructive suggestions on how to change the current negative impacts caused by the smart phones.
\end{abstract}

Keywords-smart phone; English learning; transformation; learning platform

\section{INTRODUCTION}

Due to the technological development, the smart phone has become smaller, thinner and lighter, making it a convenient and an important element of people's daily life. Together with numerous types of downloadable applications provided and advanced $3 \mathrm{~g} / 4 \mathrm{~g}$ communication technology installed, the role smart phone plays in mobile learning is becoming more and more crucial. As Dr Desmond Keegan points out, mobile learning refers that learners get access to learning resources, communicate and collaborate with others in order to construct their personal and communication network at anytime and anywhere the learners need[1].

English language learning is one of the most common phenomena for the young learners with smart phones in the mobile learning in modern times. Different from traditional learning methods, the learning method based on smart phone breaks the old framework that studying must depend on teachers, physical classrooms and physical books. With a smart phone, mobile learning allows learners to renew the ideas towards learning to fit the changing requirements of the developing society, to step out of the classrooms and to reach out to the wider world where they could get exposed to more learning resources and a broader platform to enhance comprehensive abilities in a convenient manner. However, when this new learning method gains more and more popularity, the drawbacks gradually reveal. This paper aims to discuss how to avoid the negative impacts of this learning method in the English learning process, and how to more sophisticatedly use the smart phones in English learning.
Supported by The Talent Cultivation Project for Colleges and Universities issued by Beijing (No. GJ2015065) and Course Construction of MTI: Basic Theoretical Courses (2015-2016).

\section{TRANSFORMATION OF ENGLISH LEARNING BASED ON SMART PHONE}

\section{A. Features of Smart Phone}

The smart phone is a kind of phone installed with a corresponding open operating system that makes a phone work like a computer [2]. In a combination of characteristics of the computer and original mobile phone, smart phone possesses features related to learning as portable, wirelessavailable and applications supported.

Firstly, provided either WIFI signal or $3 g / 4 g$ signal is available, a smart phone can be connected to the Internet, making online surfing experience more convenient and comfortable. Secondly, market competition and technological improvements stimulate the changes of phone's physical design, as the newest smart phone often becomes smaller and lighter. This portability feature is advantageous to carry around, compared to personal computers or pads. Thirdly, with its operation system (IOS, Android or Windows), smart phones support various types of applications, where accommodates educational and recreational functions facilitate study and daily life.

\section{B. English Learning Based on Smart Phone Applications}

According to the report on the smart phone app market, the number of educational applications has reached over 70,000 in China, accounting for $10 \%$ among all types of applications. On-line learning attracts an increasing number of English learners with its virtues of convenience and instantaneity and immediacy. Here are several samples to prove it as follows.

1) Dictionary applications: Two of the most popular vocabulary learning application types are dictionary applications and applications of helping memorize vocabulary. For dictionary part, English learners have traditionally looked up new words in physical dictionaries, such as Oxford Dictionary and Longman Dictionary that are usually heavy to carry around and time-consuming to use. However, English learners can look up vocabulary easily and readily as long as they download online dictionary applications, for example, Jinshan and Youdao, where main information on physical dictionaries is recorded. Furthermore, English learners can look up detailed word usages when connected to the Internet. More importantly, English learners can make notes on vocabulary applications and these applications can remember the words and the times of searching that users have looked up, in which way English learners can adjust their learning strategies in vocabulary learning. 


\section{PRESS}

\section{2) Vocabulary learning applications:}

The traditional way to deal with learning and memorizing vocabulary is in accordance with the curriculum standards in school. However, growing pressures brought up by diverse types of English exams or practical use in real life push English learners to memorize words as more and quickly as possible. Therefore, applications were created to help to memorize vocabularies. These applications can provide authentic contexts and make targeted plans along with efficient supervision, which contributes to guaranteeing to expand vocabulary and to resist negative effects of forgetting rules simultaneously. These vocabulary-oriented applications also offer several options to cope with the English learners' different needs and provide appropriate approaches to intriguing learning motivations. English learners can choose to download such personalized applications as they want, and choose any vocabulary type as they need, for instance, CET-4 vocabulary or living skills vocabulary, according to learners' capacity and expectations. In these applications, methods like typical example sentences, vivid pictures and interesting short videos enrich the process of memorizing vocabulary which is usually considered to be dull and mechanical. At the beginning, English learners may have problems on how to balance the relationship of memorizing new vocabulary and reviewing what they have learned, but with the help of applications on helping memorize vocabulary, which combine scientific arrangement of learning plans, periodical reviewing and learning supervision, English learners are able to promote effectiveness and efficiency of English learning beyond the class.

3) English listening applications: Similar to vocabulary learning applications, many good merits can be found in English listening applications as well, where English learners can acquire a large number of authentic English listening materials, practice listening from anywhere at any time, repeat what learners do not hear clearly at first and make personalized learning plan depending on individual situations[3]. English learners can find listening materials at different levels from VOA SPECIAL to TED, from junior high school level to CET-6 or TEM-8 level in college, and so on. What's more, different from oldfashioned radio or walkman, the smart phone has larger storage, is easier to operate and more convenient to carry around.

4) English reading applications: Most renowned mass medias have developed online readable applications so far, such as BBC News, China Daily and The Economist. Free of subscription fees and procedures, reading online magazines and reports save money and time. Apart from online reading, off-line reading with prepared reading materials can also be realized with smart phone. Installed with Office applications like WPS office or CAJ reader, pdf or txt or doc documents can be read on smart phone.

5) English speaking applications: In the old days, English learners could only practice and improve their oral English in limited ways, chatting with foreign friends or going to English corners. With interactive and communicative features of a smart phone, English speaking and listening applications provide the communication platform for English learners to find language partners and improve speaking ability, easier to implement without limitations of time and space.

\section{English Learning Feedback from Teachers Based on Smart Phone}

Except for self-learning after class, English learners need valuable and timely feedback from teachers as well to check out problems and correct them in time, when smart phone can fully take advantage of its communication function to achieve the goal.

Traditionally, portable phone realizes its communication functions through calling and sending text messages. However, with the widespread of wireless technology, people can send messages to an online community and send audio-visual messages which can be maintained regardless of time and space. This interactive feature makes linking teachers and students together after class possible, which is of great importance to complement class: teachers are able to send learning materials and class summary, and also can check students' learning status and the process of homework completion in chat groups or online community, in class or after class; to be specific, language subject teachers like English teachers can check language learners' pronunciation and communicative assignment in time by means of audio or visual messages on social platform such as WeChat and QQ. Breaking the limitations of time and space means that communication could go smoother and more efficient, in which way students are able to reflect upon their problems on English learning, especially pronunciation problems and propriety of communicative languages, by checking feedback from teachers on smart phone again and again.

\section{Positive and Negative impacts}

The new method of learning English on smart phone has both positive and negative impacts; however, the positive influence outweighs the negative one in many respects.

\section{1) Positive impacts}

More convenience and full use of small bits of time. Due to the smart phone's characteristic of convenience for carrying with and using, English learners can make the most of the time by using various types of English learning applications to enhance listening skills or chat with language exchange partners or build up small vocabulary moments when commuting, queuing and resting. English learning for foreign students is a long process which requires enduring and continuous accumulation and persistence. Firstly, Listening and speaking ability are not enhanced to a high level overnight, but are the gradual and slow process of change which happens in every small bit of time. Secondly, every vocabulary and phrase can be seen as a knowledge fragment owing to the features of large quantities and relative independence, and knowledge fragment needs collecting extensively before arranged to form a system.

a) Inspiring learning motivations: In modern times, learning in modern ways is the inevitable trend, and with modern elements, English learning on smart phone indeed inspires English learners' motivations and interest. Tired of traditional learning ways in class with fixed learning 
contents, English learners can extend their study to other interesting studying materials and learning methods depending on smart phone. The new way of learning English totally impacts the traditional one and makes English learners feel refreshing in high spirit.

b) Environmentally friendly learning mode: The realization of digital and Internet learning based on smart phone is environmentally friendly, which spends less paper and other physical learning materials. By learning on smart phone, English learners can read English passages, listen to English news and even practice oral English on the screen [4], for smart phone contains a large quantity of information with a large memory, where English learners can acquire quickly and realize recycling during learning and reviewing process.

c) A large quantity of information resources: Shared resources and access to information can be realized by using smart phones currently, where houses a large number of English learning strategies, learning materials and learning methods at the same time. Therefore, the phone based on learning carries the virtues of "Anyone, Anytime, Anywhere. Any style”[5], and in return, new learning mode associated with smart phone contributes to the great transformation of the language learning mode.

\section{2) Negative impacts}

The positive impacts of this new method of English learning are well accepted by English learners and teachers, however, the negative impacts brought by this mode are visible, which learners and teachers should realize, pay attention to and try to avoid.

a) Scattered information and unsystematic knowledge structure: Learning a language in small moments can improve the efficiency of time using, however, it makes hard for language learners to build up their own knowledge network owing to the scarce of systematic knowledge structure. Scattered materials and unsystematic structure are limited in language learning process, which only helps language learners pick up language points in pieces, rather than assist them to reorganize and construct their knowledge structure.

b) Temptations and distractions: With different levels of information and diverse types of applications on smart phone, it is indeed hard for language learners to be free of temptations on the Internet and fully focus on learning with smart phone. In most circumstances, language learners tend to transfer their concentration to Weibo or games consciously or unconsciously while using smart phone to achieve learning goals. If this phenomenon persists, language learners will abuse smart phones, and addiction to this indispensable piece of technology will become a serious issue with detrimental effects on language learners' quality knowledge acquisition and ability to concentrate for quality learning[6].

c) Difficulties to guarantee the quality of on-line learning resources: Despite the fact that the number of English learning applications and the target audience are large, due to the characteristics of low admittance standards to launch online applications, the quality and reliability of language knowledge and other learning resources included in these applications are difficult to guarantee, which leads to knowledgeable mistakes and makes users more confused on learning in some circumstances. Take dictionary applications for example, some pronunciations of the words are wrong, and the usage is improper, but English learners would not dig deep into these language points and choose to believe in the knowledge the applications provide, which misleads English learners and impedes them in further learning to some extent.

\section{How to TAKe Full AdVANTAge OF SMART PHONE IN ENGLISH LEARNING}

As mentioned above, learning English for foreign learners is a long and enduring process. Thus, students are advised to be positive and insistent during learning. Apart from adopting the correct attitude towards English learning, being objective to traditional and new methods of English learning is of utmost significance as well for English learners. At the same time, application designers and developers are also expected to take effective actions to reduce the negative impacts of English learning in a smart phone. With concerted efforts, it is possible to take full advantage of smart phone in English learning.

\section{A. Objective Attitudes towards English Learning on Smart Phone}

For English learners, they are supposed to set up the correct understanding of learning English based on a smart phone. English learners should see both aspects of learning English on smart phone and therefore it is wise to not only take full advantage of its benefits, but also recognize its limitations and drawbacks and try to avoid them. Furthermore, considering mixed levels of information, it is advised to screen quality information before using it in learning the process. Supervision system that focuses on the contents of learning materials in applications or websites is immature and incomplete at the present stage, so English learners still need to distinguish the quality of information on their own rather than believe in all that they see on a smart phone. More importantly, English learners are advised to adopt different methods of learning English. English learners cannot expect to enhance English language simply with the help of smart phone, and it is suggested to combine traditional learning methods and new learning method based on smart phone together to construct knowledge structure and complement after class at the same time, in which way learners can discard the dross and select the essence of each learning method to improve English. Finally, English learners themselves are advised to be selfrestricted when learning with smart phone. Temptations and distractions during English learning process with smart phone reduce learning efficiency, and overuse on smart phone contributes to impaired vision and other unhealthy consequences arise as time goes by, so only when they are self-restricted can English learners avoid these negative effects.

\section{B. Effective Supervision on Application}

For application designers and developers, the market share and the prospect of profits are priorities when designing and making decisions on an application. Admittedly, the innovative ideas of a product are of great importance to compete with rivals in the market, but the contents of the 
application are crucial as well. Establishing effective supervision system to supervise the correctness and properness of knowledge and language usages is necessary and advised for both application developers from internal and the application market from external.

\section{Combination of Entertainment and English Learning}

Exposed to diverse types of online information and smart phone applications, English learners can seize the opportunity to learn English combined with entertainment means. English as the most influential international language has a place in mass medias and entertainment items worldwide. Foreign TV series and reports published overseas are available resources for English learning by smart phone currently. Besides, there are increasing numbers of recreational language learning applications launched on a smart phone, with functions like dubbing, playing games and so on. Learning languages together with pleasure has transformed the traditional ways of learning languages, which motives language learners to learn and improve languages spontaneously.

\section{CONCLUSION}

With the development of mobile Internet technology and widespread use of smart phone, learning English on smart phone becomes a critical element in the background of a new era. The feature of its portability, personalized experience, entertainment attached to learning and communicative function make smart phone an advantageous device for learning, especially for language learning like English learning. However, as for the drawbacks to learning language based on smart phone, application operators are supposed to regulate and supervise their products while English learners are expected to take correct attitude towards foreign languages learning on smart phone, distinguish the quality of information on smart phone, adopt diversified learning methods and avoid overuse of smart phone and the consequential adverse effects by self-restricted means.

\section{REFERENCES}

[1] Wang Jianhua, Li Jing, Zhang Long. Mobile Learning Theory and Practice. Beijing: Science Press. 2009

[2] Wu Wenzhong, Wang Na. Smart Phones-A New Platform For Language Learning. Overseas English,2013(1):73-74

[3] Zou Cuiping. The application of smart phone in listening part of college English teaching. Journal of Jiamusi Vocational Institute, 2016(5):329

[4] Lan Bing. On the Development of Mobile English Teaching (In Chinese).Journal of Yunnan RTV University, 2009(3).

[5] Shen Yafang, Ding Gejian. The application of mobile learning in distance education. Continue Education Research (In Chinese). 2011(4).

[6] Susanne Ramadam. The Invisible Threat Smart-phone Overuse among Undergraduate English Language and Literature Majors at Sultan Qaboos University. International Journal of Technical Research and Application, 2012(8):31-32. 